\title{
En el 25 aniversario del Catecismo de la Iglesia Católica
}

\section{On the 25th Anniversary of the Catechism of the Catholic Church}

José R. VILLAR

Universidad de Navarra. Facultad de Teología

Pamplona. España

ID ORCID 0000-0002-1272-3447

jrvillar@unav.es
Resumen: Con ocasión de la celebración del vigésimo quinto aniversario de la promulgación del Catecismo de la Iglesia Católica, se ha puesto de relieve una vez más la incidencia del Catecismo Romano en los trabajos de elaboración del texto. Especialmente importante para la arquitectura del Catecismo de la Iglesia Católica ha sido la investigación histórico-dogmática sobre el Catecismo de Trento, y su posterior edición crítica, llevada a cabo por el equipo dirigido por el profesor Pedro Rodríguez de la Universidad de Navarra, cuya Facultad de Teología celebra también en estos días su quincuagésimo aniversario. Esta breve nota subraya la relevancia teológica del ordo docendi del Catecismo Romano, y su recepción en el Catecismo de la Iglesia Católica.

Palabras clave: Catecismo de la Iglesia Católica, Catecismo Romano, Universidad de Navarra.
Abstract: The 25th anniversary of the promulgation of the Catechism of the Catholic Church was an occasion to emphasize the influence exerted by the Roman Catechism over the drafting of the former. The historical-dogmatic research on the Catechism of the Council of Trent as well as its critical edition - a work published by a team directed by Pedro Rodríguez from the University of Navarra, whose Faculty of Theology recently celebrated its 50th anniversary - are particularly important for the structuring of the Catechism of the Catholic Church. This brief article highlights the theological significance of the Roman Catechism's ordo docendi and its reception in the Catechism of the Catholic Church.

Keywords: Catechism of the Catholic Church, Roman Catechism, University of Navarra. 


\section{INTRODUCCIÓN}

ए 1 pasado 11 de octubre tuvo lugar en el Aula «Pablo VI» del Vaticano, o Aula del Sínodo, la solemne conmemoración de la firma, veinticinco años antes, de la Constitución apostólica Fidei Depositum, por la que el Papa san Juan Pablo II promulgaba en 1992 el Catecismo de la Iglesia Católica. Como es sabido, el texto del Catecismo había sido aprobado por el Papa el 25 de junio de ese mismo año. La fecha elegida para la promulgación, 11 de octubre, remitía significativamente al trigésimo aniversario de la apertura del Concilio Vaticano II.

El acto conmemorativo contó con la presencia y las palabras del Papa Francisco, que dirigió un mensaje al encuentro promovido por el Pontificio Consejo para la Promoción de la Nueva Evangelización, presidido por Mons. Rino Fisichella, quien había convocado para el evento a cardenales, obispos, embajadores, teólogos, rectores y profesores, expertos en catequesis, catequistas, pastores, sacerdotes, religiosos y seminaristas, etc. A la par se había organizado en el atrio del Aula una exposición de ejemplares del Catecismo y de su Compendio publicados en diferentes lenguas.

Contemporáneamente tuvo lugar la presentación pública de un nuevo Comentario Teológico al Catecismo de la Iglesia Católica, similar al aparecido en 1993 y dirigido también ahora por Mons. Rino Fisichella ${ }^{1}$. La obra se abre con una Presentación del Papa Francisco. Comprende el texto del Catecismo, y a continuación se sitúan los comentarios teológico-pastorales a todos los artículos del Catecismo, debidos a la pluma de cuarenta autores de diferentes nacionalidades. Los comentarios van precedidos de cinco escritos sobre cuestiones introductorias: el lugar del Catecismo de la Iglesia Católica en la historia de los catecismos (G. Biancardi), su historia y estructura (R. Martinelli), sobre el Catecismo de la Iglesia Católica y la renovación catequética (J. Molinario), su recepción (C. Farey). Estas cuestiones introductorias cuentan con la aportación del cardenal Christoph Schönborn, arzobispo de Viena, que se ocupa de tratar del tema del Catecismo de la Iglesia Católica en las Iglesias particulares. Como es sabido, el cardenal austríaco fue en su

${ }^{1}$ Fisichella, R. (a cura di), Catechismo della Chiesa Cattolica. Testo integrale. Nuovo commento teologico-pastorale, Roma: Libreria Editrice Vaticana-San Paolo, 2017. El anterior comentario era: FIsichella, R. (a cura di), Commento teologico al Catechismo della Chiesa Cattolica, Casale Monferrato: Piemme, 1993. Entre otros comentarios, vid. ARANDA, A. (ed.), «Creemos y conocemos»: lectura teológica del Catecismo de la Iglesia Católica, Pamplona: Eunsa, 2012. 
momento -todavía profesor de teología en Friburgo, Suiza- el Secretario de la Comisión de obispos y cardenales encargados de la elaboración del Catecismo, y presidida por el entonces Prefecto de la Congregación para la Doctrina de la Fe, cardenal Joseph Ratzinger. Precisamente el cardenal Schönborn, durante su intervención oral en el Aula Pablo VI, explicó algunos criterios que guiaron la estructura y elaboración del Catecismo de la Iglesia Católica; son los criterios que aparecen expuestos en su aportación al citado Comentario $^{2}$.

Concretamente, el cardenal se refirió en el Aula a la importancia que tuvo en el planteamiento global del Catecismo de la Iglesia Católica la investigación histórico-dogmática sobre el Catecismo Romano llevada a cabo desde la Facultad de Teología de la Universidad de Navarra, y que culminó con la edición crítica del célebre texto mandado publicar por el Concilio de Trento. Era esta edición crítica el fruto de una amplia tarea llevada a cabo durante años en la Facultad de Navarra por un equipo de colaboradores dirigido por el profesor Pedro Rodríguez, entre los que destacaba el prof. Raúl Lanzetti (fallecido en su patria Argentina en 2004). La edición crítica fue posible por el hallazgo del manuscrito original del Catecismo Romano durante una de las estancias del profesor Rodríguez en la Biblioteca Apostólica Vaticana, y que constituía la pieza que completaba la documentación para realizar la edición.

En su aportación al citado Comentario, el cardenal Schönborn valora la incidencia de la edición crítica -en realidad, de la entera investigación que ésta presuponía- para las labores redaccionales del Catecismo de la Iglesia Católica. Reproducimos esos párrafos en nuestra versión española.

«Aquí es oportuno lanzar una mirada a la edición crítica del Catecismo Romano, un trabajo científico notable y enriquecedor, llevado a cabo por dos investigadores del Opus Dei. Pedro Rodríguez y Raúl Lanzetti encontraron en la Biblioteca Vaticana el original manuscrito del Catecismo Romano, que se pensaba desaparecido, y a partir de esta base llevaron a cabo la primera edición crítica de tal catecismo. En las investigaciones previas a esta edición, dichos investigadores precisaron elementos importantes también válidos para el nuevo CEC [= Catecismo de la Iglesia Católica]. Es sabido que el Catecismo Romano ha sido el modelo para la estructura del CEC. Pedro Rodríguez

\footnotetext{
${ }^{2}$ SCHÖnboRn, Ch., «Il Catechismo della Chiesa Cattolica nelle Chiese particolari», ibid., 813-824.
} 
y Raúl Lanzetti han mostrado que esta estructura está más que justificada. No es justificable, por ejemplo, que los diez mandamientos aparezcan colocados ante todo en la segunda sección. En la tradición catequética latinoamericana, y también francesa, está presente una clara tendencia a tratar de los mandamientos antes que de los sacramentos. Precisamente como hace Lutero en su Catecismo. El Catecismo Romano sigue aquí otro modelo, y se trata de una aplicación directa de la jerarquía de las verdades: fe y sacramentos, la fides y los fidei sacramenta vienen primero de todo, luego, a continuación, los mandamientos y la oración. Raúl Lanzetti y Pedro Rodríguez han mostrado que el Catecismo Romano, en realidad, no está subdividido en cuatro secciones, sino más bien en dos, de modo semejante a un díptico, en que una de las tablas expone la acción de Dios, como se nos presenta en el Credo, y las grandes obras de Dios que se nos comunican en los sacramentos. La segunda tabla del díptico representa la respuesta del hombre. Es particularmente significativo el hecho, como han demostrado estos dos investigadores, que de este modo el Concilio de Trento, o sea, la Comisión encargada de la redacción del Catecismo, ha querido responder a las provocaciones de la Reforma» ${ }^{3}$.

Esta mención del cardenal Schönborn al significado de la edición crítica del Catecismo Romano para la elaboración del Catecismo no era nueva. Con ocasión de su investidura como Doctor honoris causa por la Universidad de Navarra, el 31 de enero de 1998, a la laudatio del nuevo Doctor que dirigió el profesor Pedro Rodríguez respondía el cardenal Joseph Ratzinger con estas palabras: «Usted, Profesor Rodríguez, con el descubrimiento y la edición crítica del manuscrito original del "Catecismo Romano", ha prestado a la teología un servicio que trasciende unas concretas circunstancias históricas, y que ha revestido también gran importancia para mis trabajos durante la preparación del "Catecismo de la Iglesia Católica" » .

Con ocasión del 50 aniversario de la Facultad de Teología de la Universidad de Navarra -que estamos celebrando gozosamente durante este año de 2017-, vale la pena recordar en líneas generales esta tarea señera en la breve historia de nuestra Institución académica, como estímulo para el trabajo presente y futuro.

\footnotetext{
${ }^{3}$ SChÖnBorn, Ch., «Il Catechismo della Chiesa Cattolica nelle Chiese particolari», 817.

${ }^{4}$ Discurso del Emmo. y Revmo. Cardenal Dr. Joseph Ratzinger, Scripta Theologica 30 (1998) 387.
} 


\section{LA INVESTIGACIÓN HISTÓRICO-DOGMÁTICA SOBRE EL CATECISMO ROMANO}

Desde finales de la década de los años setenta del pasado siglo, el Departamento de Eclesiología de la Facultad de Teología de la Universidad de Navarra dirigió su atención al Catecismo mandado elaborar por el Concilio de Trento. Con ese fin promovió a lo largo de varios años un Seminario de Estudios sobre la teología eclesiológica y sacramentaria del Catecismo Romano ${ }^{5}$.

La perspectiva de estas sesiones de estudio del Seminario se centraba en el aspecto histórico-dogmático antes que en la perspectiva pastoral-catequética. No obstante, el estudio científico y riguroso del Catecismo pronto evidenció que era necesario también atender a la historia redaccional del texto, e indagar sus fuentes y modelos literarios. De ese modo la investigación teológica condujo de manera natural a afrontar la labor de fijación del texto mismo, de su estructura e historia.

Los resultados de esos trabajos quedaron reflejados en un amplio volumen de estudios publicado en 1982 por Pedro Rodríguez y Raúl Lanzetti en las Ediciones de la Universidad de Navarra, con el título El Catecismo Romano: fuentes e historia del texto y de la redacción. Bases críticas para el estudio teológico del catecismo del Concilio de Trento (1566). Con esta publicación sus autores ponían a disposición de los estudiosos la base metodológica que facilitase la realización de investigaciones posteriores. De ese modo, en la Facultad de Teología de Pamplona se pudieron llevar a cabo estudios histórico-dogmáticos sobre contenidos particulares del Catecismo Romano ${ }^{6}$.

Sin embargo, se echaba en falta la existencia de una edición crítica puesto que «el Catecismo Romano, a lo largo de cuatro siglos -comentaban los autores en 1982- ha sido objeto de cientos de ediciones en su original latino y en traducciones a las principales lenguas de la Cristiandad. (...) Esta multipli-

\footnotetext{
${ }^{5}$ El profesor Rodríguez pronto se interesó por algún aspecto particular del Catecismo Romano, cfr. RodríguEZ, P., «El sentido de los sacramentos según el Catecismo Romano», Scripta Theologica 9 (1977) 951-984. Se trataba de una ponencia presentada a la XXVII Semana Española de Teología (Madrid, 1976). De manera similar, el entonces doctorando Raúl Lanzetti dedicó su Tesis de Doctorado a La doctrina sobre la Penitencia en el Catecismo Romano (pro manuscripto, Pamplona, 1979).

${ }^{6}$ Así, entre otras, las Tesis de Doctorado de Domingo, F. J., «El sacramento del Bautismo y las fuentes redaccionales del Catecismo Romano», Excerpta e dissertationibus in Sacra theologia 18 (1990) 223-309; AsEnjo, M., «Los dictámenes sobre el Símbolo de los Apóstoles del Catecismo Romano: su elaboración, ejecución y trasfondo teológico», ibid., 17 (1990) 393-444; MARTíNEZ, M., «Doctrina sobre la oración en la cuarta parte del Catecismo Romano», ibid., 24 (1993) 71142; GARRIDO, A., «La Eucaristía según el Catecismo Romano», ibid., 49 (2006) 105-187.
} 
cidad de ejemplares plantea inmediatamente el problema mismo del texto, cosa que se hace evidente en cuanto comienza la consulta de los diversos testigos y empiezan a aparecer diferencias: se tiene enseguida la impresión de que existen tradiciones editoriales diversas y como familias en la transmisión y estructuración del texto»; pero la empresa de realizar una edición crítica -seguían comentando- no era posible en ese momento «y en sentido estricto, parece difícil que pueda llegar a establecerse. La razón es muy sencilla. La historia de la redacción, (...) no nos ofrece los materiales concretos de sus distintas fases y, lo que es más importante, hasta el momento no ha podido encontrarse el manuscrito que sirvió de base a la primera edición. Este manuscrito, que sería el punto de partida obligado para esa posible edición crítica, tal vez se encuentre en algún archivo romano, probablemente en los archivos vaticanos. Pero de él sólo se sabe hasta ahora que, después de haber sido utilizado en la imprenta de Paulo Manucio, obraba en poder del Cardenal Sirleto, Presidente de la Comisión que hizo la última revisión del texto. Éste, con fecha 12 de noviembre de 1566 y con ocasión de marcharse de Roma hacia su nueva diócesis, encargó a su hermano Jerónimo que entregase el manuscrito a Tomás Manrique O.P., Maestro del Sacro Palacio, pues a él le correspondería conservarlo. No sabemos si Jerónimo Sirleto cumplió el encargo. El caso es que de esos folios nada ha vuelto a saberse» ${ }^{7}$.

En realidad, el destino del manuscrito original del Catecismo Romano era un enigma que Paschini y Jedin, célebres historiadores del Concilio de Trento, no pudieron resolver durante sus búsquedas en el Archivo Vaticano.

\section{El manuscrito original del Catecismo Romano}

Así las cosas, el asunto tuvo un giro inesperado cuando en la mañana romana del 26 de abril de 1985 el profesor Rodríguez se topó con el manuscrito original del Catecismo Romano entre los fondos manuscritos latinos de la Biblioteca Apostólica Vaticana. El descubrimiento del precioso Códice Vat. Lat. 4994 se unía al hallazgo por el profesor Lanzetti, unos meses antes y en la misma Biblioteca Vaticana, de unos extensos dictámenes sobre el manuscrito original.

${ }^{7}$ Rodríguez, P. y LANZetTi, R., El Catecismo Romano: fuentes e historia del texto y de la redacción. Bases críticas para el estudio teológico del catecismo del Concilio de Trento (1566), Pamplona: Eunsa, 1982, 205-207. 
Inmediatamente los dos investigadores dieron noticia del descubrimiento a la comunidad científica. Esta Revista dedicó un Cuaderno monográfico al acontecimiento en el fascículo 2 del volumen 17 (1985). En esas páginas Rodríguez y Lanzetti informaron de los datos referentes al manuscrito, así como también sobre el nuevo material relativo al Catecismo Romano que habían ido conociendo desde el estudio publicado en 1982. También exponían la cuestión histórico-doctrinal del Catecismo Romano, la historia del descubrimiento del manuscrito original, los dictámenes sobre el manuscrito del Catecismo Romano, y sobre todo anunciaban el inicio de los trabajos de la edición crítica del Catecismo Romano, que era finalmente posible ${ }^{8}$. Este Cuaderno de Scripta Theologica fue publicado contemporáneamente en las Ediciones Universidad de Navarra en forma de libro autónomo, con el título: El manuscrito original del Catecismo Romano. Descripción del material y los trabajos al servicio de la edición crítica del Catecismo del Concilio de Trento (1985).

A partir de ese momento se constituyó en el Departamento de Eclesiología de la Universidad de Navarra un equipo de investigación en orden a la preparación de la edición crítica, formado por profesores del Departamento de Eclesiología y del Instituto de Historia de la Iglesia de la Facultad.

\section{La Elaboración de la EDICIÓn CRÍTiCA DEl CATECISMO Romano}

El profesor Rodríguez explicaba en el citado Cuaderno de Scripta Theologica el plan de trabajo previsto para la edición crítica, y el equipo de personas que lo llevarían a cabo.

En síntesis, el trabajo que habría de realizarse se proponía el siguiente objetivo: «el ejemplar del CR [= Catecismo Romano] que preparamos tendrá, según nuestros planes, dos grandes partes: la primera intentará establecer el texto del Catecismo, anotado; la segunda recogerá abundante documentación complementaria. La información científica que -en torno a esos dos grandes sectores del libro- se desea ofrecer en la edición que proyectamos responde a los siguientes apartados: 1. Ante todo, "el” texto del CR. 2. Documentación crítica del texto: citas explícitas e implícitas de la Escritura, los Padres, los

\footnotetext{
${ }^{8}$ Cfr. Rodríguez, P., «La cuestión histórico-doctrinal del Catecismo Romano», Scripta Theologica 17 (1985) 467-486; LANZETTI, R. «Los dictámenes sobre el manuscrito del Catecismo Romano», ibid., 553-600; RodRíGUEZ, P., «El manuscrito original del Catecismo Romano», ibid., 487552; RodríGueZ, P., «Los trabajos de la edición crítica del Catecismo Romano», ibid., 601-618.
} 
Doctores, y el Magisterio de Papas y Concilios. 3. Elementos para la comprensión teológica del CR, en un doble nivel: a) la teología del CR comprendida desde la redacción manuscrita; b) la recepción teológica del CR manifestada en la tradición impresa»? .

En cuanto al equipo de trabajo, se decía: «La empresa de la edición crítica del CR pide, como todo trabajo científico de envergadura, aparte de la financiación necesaria, un equipo de hombres que la realice. El equipo nuclear para la edición crítica está formado por el Prof. Ildefonso Adeva, Canónigo de la Catedral de Pamplona, experto latinista y estudioso de la espiritualidad y la teología del siglo XVI, y el Dr. Francisco Domingo, que este año ha leído en el Departamento su tesis doctoral sobre la teología del Bautismo en la tradición catequética del siglo XVI: ambos están en inmejorables condiciones para el trabajo proyectado; desde Roma prestará su colaboración imprescindible el Prof. Lanzetti, y en Pamplona yo me encargaré de la dirección y coordinación de los trabajos. Un grupo de doctorandos de la Facultad de Teología ayudará también en el trabajo. La relación interdisciplinar del Departamento de Eclesiología con el Instituto de Historia de la Iglesia nos asegura algunos subsidia scientifica imprescindibles. Nuestro plan apunta a terminar los trabajos en junio de $1988 \gg^{10}$.

La elaboración de la edición crítica pudo llevarse a cabo según el plan y plazos previstos. Como cinco años después explicaría el profesor Rodríguez en el Prólogo a la edición crítica, la tarea se desarrolló en continua interacción de los colaboradores. «El latinista Prof. I. Adeva emprendía la dura tarea de transcribir el primer borrador del Catecismo, poner en correcto latín la Introducción y los comentarios a los dictámenes y hacer el index rerum, a la vez que aseguraba la propiedad latina de todo el conjunto. El Prof. R. Lanzetti transcribía la mayor parte de los dictámenes y contribuía decisivamente a la reflexión sobre el proceso redaccional del Catecismo. El Prof. F. Domingo coordinaba la colaboración de doctorandos y estudiantes, transcribía buena parte de los marginalia del "textus receptus" y, sobre todo, se aplicaba al tratamiento tecnológico de toda la investigación. El patrólogo Prof. M. Merino, que se incorporó más adelante a los trabajos, se dedicó a la nada cómoda tarea de investigar y documentar el patrimonio bíblico, patrístico y magisterial del texto, y preparar los índices correspondientes. A mí, como Director del proyecto, me correspondía la planificación de la edición, la coordinación y revisión de los trabajos y, por otra par-

\footnotetext{
9 Rodríguez, P., «Los trabajos de la edición crítica del Catecismo Romano», 607.

10 Ibid., 612.
} 
te, preparar la Introducción y los Comentarios a los dictámenes y reunir la Documentación complementaria. El establecimiento del texto crítico, en cuanto tal, se realizó en periódicas sesiones a lo largo del curso 1985-86, en las que colaboraron nuestros alumnos y en las que los Profs. Adeva, Domingo y yo decidíamos en última instancia los problemas críticos. Por otra parte, la interpretación del proceso redaccional, de tan grave incidencia para la historia del texto e incluso para la estructura de nuestra edición, era objeto de frecuentes reflexiones que hacíamos en Roma el Prof. Lanzetti y yo, con ocasión de las nuevas fuentes manuscritas que iban apareciendo en la Biblioteca Apostólica y en el Archivo Secreto Vaticano, y en la Biblioteca Ambrosiana de Milán» ${ }^{11}$.

\section{LA PUBLICACIÓN DE LA EDICIÓN CRÍTICA}

En 1989 se culminaba la tarea con la aparición de la edición crítica, publicada en coedición de la Libreria Editrice Vaticana y Ediciones Universidad de Navarra. Lleva el título siguiente:

Catechismus Romanus seu Catechismus ex Decreto Conciiii Tridentini ad Parochos Pii Quinti Pont. Max. iussu editus. Editioni praefuit Petrus Rodríguez. Eam instruendam atque apparandam item curaverunt IIdephonsus Adeva, Franciscus Domingo, Radulfus Lanzetti et Marcellus Merino, Roma: Libreria Editrice Vaticana-Ediciones Universidad de Navarra, MCMLXXXIX, encuadernado en tela, LXXX + 1378 págs., 26 ilustraciones, $21 \times 28 \mathrm{~cm}$.

Naturalmente nuestra Revista se hacía eco del evento en el fascículo 2 de su volumen 22 de 1990 (pp. 539-594). El acontecimiento se presentaba con las siguientes palabras: «La aparición en Roma de este importante volumen, coeditado por la Libreria Editrice Vaticana y Ediciones Universidad de Navarra, constituye tal vez el acontecimiento más destacado del año en el campo de la edición de fuentes teológicas. Con este motivo el día 20 de junio los autores fueron recibidos en audiencia especial por S.S. Juan Pablo II. También presentaron su trabajo al Gran Canciller de la Universidad de Navarra. Scripta Theologica se honra publicando el original castellano del Prólogo y de la Introducción al texto crítico, preparados por el Prof. Pedro Rodríguez, cuya tra-

${ }^{11}$ Scripta Theologica 22 (1990) 540. 
ducción latina, obra del Prof. Ildefonso Adeva, es la que aparece en la Edición Crítica. En el citado prólogo, se describe detenidamente el equipo científico que ha realizado esta formidable tarea (...) Scripta Theologica sabe, por otra parte, que al ofrecer estos textos en lengua vulgar amplía a nuevos lectores el acceso a la consulta de la Edición Crítica» ${ }^{12}$.

\section{La edición CRítica Y el Catecismo de la Iglesia Católica}

De manera imprevista el hallazgo del manuscrito original y el proyecto de edición crítica habían coincidido en el tiempo con el vigésimo aniversario de la clausura del Concilio Vaticano II y la convocatoria de un Sínodo Extraordinario de los Obispos para analizar la aplicación del Concilio en esos veinte años, que precisamente solicitó la preparación de lo que llegaría a ser el Catecismo de la Iglesia Católica. El Prólogo del profesor Rodríguez a la edición crítica menciona esta circunstancia providencial.

«En 1985, el mismo año en que aparecieron los manuscritos originales del Catecismo Romano, el Sínodo Extraordinario de los Obispos (25-X a 8-XII de 1985) iba a proponer formalmente al Papa Juan Pablo II -que aceptaba, nombrando una Comisión redactora- la preparación de un nuevo Catecismo para la Iglesia Universal. Por segunda vez en su historia, la Iglesia Católica se adentraba en esta ardua tarea, cuyo proceso está en marcha: formular una síntesis catequética de la fe dentro de las coordenadas culturales y pastorales de nuestra época. En este sentido, la edición que ahora sale a la luz ofrece a los pastores y a los teólogos un texto fidedigno del primer Catecismo de la Iglesia Universal, y algo también -dentro de los cánones rigurosos de este tipo de ediciones- de la experiencia histórica y eclesial que vivieron los hombres que lo llevaron a cabo, también pastores y teólogos, algunos de ellos santos canonizados por la Iglesia» ${ }^{13}$.

\section{a) La incidencia del Catecismo Romano en la elaboración del nuevo Catecismo}

Como es bien conocido, una vez promulgado el Catecismo de la Iglesia Católica por san Juan Pablo II, el 11 de octubre de 1992, tanto el card. Ratzinger como el ahora cardenal Schönborn, en su calidad de Presidente y

12 «La edición crítica del Catecismo Romano», Scripta Theologica 22 (1990) 539.

13 Ibid., 542. 
Secretario respectivamente de la Comisión redactora, tuvieron que exponer y glosar la historia y el significado del Catecismo de la Iglesia Católica en multitud de conferencias y escritos. Fue recurrente en todas sus intervenciones $-\mathrm{y}$ también en las de otros estudiosos del Catecismo ${ }^{14}$ - la referencia a la edición crítica del Catecismo Romano, y a la investigación previa que la sostenía.

Por ejemplo, en 1993 el card. Ratzinger, al exponer la génesis y redacción del Catecismo, mencionaba una de las primeras tareas que afrontó la Comisión redactora del Catecismo, a saber, el título que habría de llevar la obra: sería ¿Catecismo o Compendio? En realidad, no era ésta una mera cuestión nominal, sino que tras ella -explicaba el cardenal- se decidía el tipo de destinatarios a los que debería dirigirse, y en consecuencia su método y género literario. La cuestión vino a clarificarse con lo sucedido con el Catecismo Romano, según las investigaciones expuestas por Rodríguez-Lanzetti en Fuentes e historia, que el cardenal conocía de primera mano ${ }^{15}$.

La remisión reiterada al Catecismo Romano sucede sobre todo en relación con la estructura del Catecismo de la Iglesia Católica. Seguía diciendo el cardenal que «en el curso de nuestras conversaciones, la división en cuatro partes del Catecismo de Trento -confesión de fe, sacramentos, mandamientos, oración- mostró ser, hoy como antes, la vía más adecuada para un Catechismus maior (...). Para sorpresa nuestra resultó que en esta aparente yuxtaposición de piezas hay que reconocer absolutamente algo así como un "sistema". Se presenta sucesivamente lo que la Iglesia cree, lo que celebra, lo que vive,

${ }^{14}$ Baste referirnos, limitados a España, a las aportaciones contenidas en GONZÁLEZ DE CARDEDAL, O. y Martínez Camino, J. A., El Catecismo postconciliar. Contexto y contenidos, Madrid: San Pablo, 1993.

${ }^{15}$ Cfr. al respecto Ratzinger, J., «Introducción al Catecismo de la Iglesia Católica», en RatzinGER, J. y SCHÖnborn, Ch., Introducción al Catecismo de la Iglesia Católica, Madrid: Ciudad Nueva, 1993, 16-18. Se observa la familiaridad del cardenal con la obra Fuentes e historia en las consideraciones que ya dedicaba en 1983 a la estructura de la tradición catequética en sus célebres conferencias dictadas en París y Lyon sobre la catequesis actual, cfr. RATZINGER, J., Die Krise der Katechese und ibre Überwindung, Einsiedeln: Johannes Verlag, 1983, 31; vid. la versión española de estas conferencias en: «Transmisión de la fe y fuentes de la fe», Scripta Theologica 15 (1983) 9-29. Nuestra Revista acompañaba esas importantes reflexiones del cardenal Ratzinger con la siguiente nota editorial (p. 9): «Este texto es la traducción castellana de la conferencia que el autor pronunció en Lyon y París los días 15 y 16 de enero del presente año 1983. La traducción ha sido realizada por el Director de la Revista Prof. Dr. Pedro Rodríguez, a partir del original alemán, todavía inédito, que el Cardenal Ratzinger ha tenido la amabilidad de enviarnos. Este original contiene algunos desarrollos no incluidos en el texto francés, que ha sido publicado en $\mathrm{La}$ Documentation Catholique 65 (1983) 260-267. La Redacción de Scripta Theologica agradece al Cardenal Prefecto de la S. C. para la Doctrina de la Fe la autorización para publicar en nuestra Revista la versión castellana de esta importante exposición doctrinal». 
cómo ora» ${ }^{16}$. Por su parte, Ch. Schönborn explicaba: «El plan de este Catecismo [CEC] constaba, al principio, de tres partes. Más tarde se le añadió una cuarta parte, siguiendo el modelo del Catecismo Romano. Los editores de la edición crítica de este último, Pedro Rodríguez y Raúl Lanzetti, explican muy bien el sentido de la opción realizada por los redactores del Catecismo de Trento: subrayan el hecho de que el orden de las cuatro partes reviste gran importancia teológica» ${ }^{17}$.

\section{b) La estructura del Catecismo de la Iglesia Católica}

En efecto, una de las aportaciones preciosas de la investigación llevada a cabo durante esos años en la Facultad en torno al Catecismo Romano fue poner de relieve, con buenos fundamentos, la opción estructural del Catecismo de Trento, y que sirvió de plan estructural del Catecismo de la Iglesia Católica al que se refería el cardenal Schönborn.

El significado teológico de esa opción del Catecismo Romano viene resumida por el prof. Rodríguez en la Introducción (en latín) a la edición crítica, que reproducimos ahora en la versión castellana preparada por nuestra Revista.

Según Rodríguez, «la peculiar penetración del Catecismo Romano en el nexus mysteriorum de la fe aparece ya en su ordo docendi (...). El estudio teológico del Catecismo Romano y de su contexto histórico lleva a la convicción de que su ratio doctrinae es fruto de una muy pensada elección, que busca captar la entraña de la economía revelada y expresarla con rigor teológico. El ordo del Catecismo Romano es: 1. El Símbolo de la fe; 2. Los sacramentos; 3. El Decálogo; 4. El Padrenuestro. Su originalidad respecto a la catequética precedente -me refiero a la catequética polémica con el protestantismo y, por supuesto, a los catecismos protestantes- consiste en situar la doctrina sobre los sacramentos no sólo después del Símbolo de la Fe, sino precisamente entre el Símbolo y el Decálogo. Esta consideración es clave para la inteligencia del conjunto. (...) El itinerario teológico del Catecismo Romano, que ha unido estrechamente "la fe y los sacramentos de la fe", como diría Tomás de Aquino, no puede ser enteramente comprendido si no se capta además por qué los sacramentos se exponen antes que el Decálogo. $\mathrm{O}$, mejor: si no se capta por qué

${ }^{16}$ Cfr. ibid., 31.

17 Schönborn, Ch., «Criterios de redacción del Catecismo», en González de Cardedal, O. y Martínez Camino, J. A., El Catecismo postconciliar. Contexto y contenidos, Madrid: San Pablo, $1993,84$. 
el Decálogo sólo puede comprenderse cristianamente a partir de la doctrina sobre los sacramentos. En la opción de los redactores del Catecismo late la concepción católica de la justificación, que viene expuesta al filo de la doctrina sobre el Bautismo y la Penitencia: la gracia y las virtudes, que el Catecismo llama con San Pablo "pignus Spiritus Sancti", constituyen al hombre en nueva criatura. (...). El Catecismo enseña que las obras de justicia señaladas en el Decálogo, y que son las obras del amor, proceden de las virtudes, y que éstas se nos dan, se recuperan y se aumentan celebrando los sacramentos. En consecuencia, el Catecismo Romano ordena el patrimonio tradicional de la doctrina cristiana a partir de ésta su fundamental convicción, y aparecen así los sacramentos como el puente que permite transitar al hombre y a la Iglesia desde la fe a las obras de la fe. Como se ve, el ordo doctrinae del Catecismo Romano, en el fondo, no tiene cuatro partes, sino que se ofrece en un grandioso díptico tomado de la Tradición: por una parte, los misterios de la fe en el Dios Uno y Trino profesados (Símbolo) y celebrados (Sacramentos); por otra, la existencia humana en la fe -la "fides quae per charitatem operatur"- desplegada en conducta cristiana (Decálogo) y oración filial (Padre Nuestro)» ${ }^{18}$.

He aquí, en síntesis, el fundamento de la opción teológica que convenció al card. Ratzinger, y que asumirá el Comité de redacción del Catecismo de la Iglesia Católica, tal como relata el entonces Secretario, remitiéndose al Prólogo (en realidad, Introducción) del prof. Rodríguez a la edición crítica. Schönborn lo hace en los siguientes términos, que merece la pena recoger por extenso.

«El año 1989 apareció la edición crítica del Catechismus Romanus (CR), el llamado "Catecismo del Concilio de Trento", dado a luz pública por primera vez el año 1566. El editor, prof. Pedro Rodríguez, y sus colaboradores han investigado muy cuidadosamente los fundamentos para el plan y las decisiones fundamentales de los autores del CR. (...) A la disposición fundamental del CEC podemos aplicar lo que Pedro Rodríguez escribe sobre el plan del CR: "La opción es evidente: el CR, antes de presentar al cristiano lo que ha de hacer, quiere declararle quién y cómo es él, hallamos esta cita de san León Magno: 'Reconoce, cristiano, tu dignidad'. Sólo cuando reconoce el poder sobrenatural que mana de su 'ser en Cristo a través del Espíritu Santo', el creyente discípulo de Cristo puede hacer el esfuerzo, con un corazón confiado, sin temor servil, de practicar y de hacer crecer la vida cristiana según el decálogo... Sin la doctrina preceden-

${ }^{18}$ RodrígueZ, P., «La edición crítica del Catecismo Romano», Scripta Theologica 22 (1990) 548552. 
te de los sacramentos -la cual implica también la enseñanza sobre el Misterio de la Iglesia y de la justificación- los preceptos del decálogo parecen exceder nuestra capacidad humana. Pero, basándonos en la fe y los sacramentos, los miramos con confianza y vigor. Ésta es una propiedad específica de la espiritualidad católica, que alcanza su punto culminante en el CR" (prólogo, pp. XXVI-XXVII). También podemos trasladar el siguiente análisis al CEC: "De hecho, el orden doctrinal del CT no tiene cuatro partes, sino que se presenta como un díptico magnífico tomado de la tradición: por un lado, los misterios de la fe en Dios uno y trino, tal como es profesada (Credo) y celebrada (sacramentos); por otro lado, la vida cristiana según la fe -fe que obra por la caridad- expresada en un estilo cristiano de vida (decálogo) y en una oración filial (Padre Nuestro)" (prólogo, p. XXVIII). El mensaje de este díptico es claro: tanto el CR como el CEC destacan inequívocamente el primado de la gracia. (...) Cualquiera que sea el método que se emplee en la catequesis -el CR y el CEC no imponen ningún método específico-, se ha de dar el primado a Dios y a sus obras. Sea lo que fuere lo que el hombre tiene que hacer, siempre será una respuesta a Dios y a sus obras. En ambos Catecismos son las proezas de Dios el tema de que propiamente se trata. Hasta aquí hay una clara opción catequética, que no queda simplemente a elección, sino que cae de su peso, pues corresponde a la realidad: Dios viene primero; la gracia viene primero. Ésa es la verdadera jerarquía de verdades» ${ }^{19}$.

Este «plano de construcción», como lo llama Schönborn, o «construcción cuatripartita como estructura orgánica de conjunto», la pone en relación el cardenal austríaco con el principio conciliar del orden o «jerarquía» de verdades (cfr. Decr. Unitatis redintegratio n. 11). En efecto, ese ordo docendi -por usar la fórmula del prof. Rodríguez- ayuda a captar la conexión de las afirmaciones particulares con el fundamento de la fe católica, tal y como dice el Concilio Vaticano II en su célebre texto sobre la hierarchia veritatum. En realidad, el mismo ordo docendi u «opción estructural», como señala el cardenal, «contiene ya un mensaje (...) está fundada en la cosa misma» ${ }^{20}$.

La importancia de la estructura expositiva se evidencia también en la Const. apost. Fidei Depositum, cuando san Juan Pablo II dedica uno de los cinco párrafos que la componen precisamente a glosar la «distribución de la materia» del Catecismo (n. 3). «El Catecismo de la Iglesia Católica -afirma el Papa-por

19 SCHÖNBORN, Ch., «El Catecismo de la Iglesia Católica: ideas directrices y temas fundamentales», en Ratzinger, J. y SchÖnborn, Ch., Introducción al Catecismo de la Iglesia Católica, Madrid: Ciudad Nueva, 1993, 52-56.

${ }^{20} \mathrm{Ibid} ., 52$. 
una parte recoge el orden antiguo, tradicional, y seguido ya por el Catecismo de san Pío V, dividiendo el contenido en cuatro partes: el Credo, la Sagrada Liturgia, con los Sacramentos en primer plano; el obrar cristiano, expuesto a partir de los mandamientos, y, finalmente, la oración cristiana. (...). Las cuatro partes se articulan entre sí: el misterio cristiano es el objeto de la fe (primera parte); es celebrado y comunicado mediante acciones litúrgicas (segunda parte); está presente para iluminar y sostener a los hijos de Dios en su obrar (tercera parte); es el fundamento de nuestra oración, cuya expresión principal es el "Padre Nuestro", que expresa el objeto de nuestra súplica, nuestra alabanza y nuestra intercesión (cuarta parte). La liturgia es, por sí misma, oración; la confesión de fe tiene su justo lugar en la celebración del culto. La gracia, fruto de los sacramentos, es la condición insustituible del obrar cristiano, igual que la participación en la liturgia de la Iglesia requiere la fe. Si la fe no se concreta en obras permanece muerta (cfr. St 2,14-26). Y no puede dar frutos de vida eterna $\gg^{21}$.

En realidad, el alcance hermenéutico de la estructura expositiva viene ya subrayado por el mismo Catecismo, cuando en su Prólogo dedica los nn. 13-17 del epígrafe IV a explicar la significativa «estructura» teológica del Catecismo:

$\ll$ El plan de este Catecismo se inspira en la gran tradición de los catecismos, los cuales articulan la catequesis en torno a cuatro "pilares": la profesión de la fe bautismal (el Símbolo), los sacramentos de la fe, la vida de fe (los Mandamientos), la oración del creyente (el Padre Nuestro). Primera PARTE: LA PROFESIÓN DE LA FE. Los que por la fe y el Bautismo pertenecen a Cristo deben confesar su fe bautismal delante de los hombres (cfr. Mt 10,32; Rom 10,9). Para esto, el catecismo expone en primer lugar en qué consiste la Revelación por la que Dios se dirige y se da al hombre, y la fe, por la cual el hombre responde a Dios (primera sección). El Símbolo de la fe resume los dones que Dios hace al hombre como Autor de todo bien, como Redentor, como Santificador y los articula en torno a los "tres capítulos" de nuestro Bautismo -la fe en un solo Dios: el Padre Todopoderoso, el Creador; y Jesucristo, su Hijo, nuestro Señor y Salvador; y el Espíritu Santo, en la Santa Iglesia- (segunda sección). SEgUnda PARTE: LOS SACRAMENTOS DE LA FE. La segunda parte del catecismo expone cómo la salvación de Dios, realizada una vez por todas por Cristo Jesús y por el Espíritu Santo, se hace presente en las acciones sagradas de la liturgia de la

${ }^{21}$ SAn Juan Pablo II, Const. apost. Fidei Depositum (11-IX-1992), n. 3. 
Iglesia (primera sección), particularmente en los siete sacramentos (segunda sección). TERCERA PARTE: LA VIDA DE FE. La tercera parte del catecismo presenta el fin último del hombre, creado a imagen de Dios: la bienaventuranza, y los caminos para llegar a ella: mediante un obrar recto y libre, con la ayuda de la ley y de la gracia de Dios (primera sección); mediante un obrar que realiza el doble mandamiento de la caridad, desarrollado en los diez mandamientos de Dios (segunda sección). CUARTA PARTE: LA ORACIÓN EN LA VIDA DE LA FE. La última parte del catecismo trata del sentido y la importancia de la oración en la vida de los creyentes (primera sección). Se cierra con un breve comentario de las siete peticiones de la oración del Señor (segunda sección). En ellas, en efecto, encontramos la suma de los bienes que debemos esperar y que nuestro Padre celestial quiere concedernos».

Precisamente el Papa Francisco, en su discurso en el Aula del Sínodo a los participantes en el acto conmemorativo del pasado 11 de octubre, reiteraba que esta estructura expositiva conduce por sí misma a una determinada finalidad, que es la comunión amorosa del hombre con Dios. «El Catecismo de la Iglesia Católica, al delinear los puntos estructurales que lo componen, retoma un texto del Catecismo Romano, lo hace suyo, proponiéndolo como clave de lectura y de aplicación: "Toda la finalidad de la doctrina y de la enseñanza debe ser puesta en el amor que no acaba. Porque se puede muy bien exponer lo que es preciso creer, esperar o hacer; pero sobre todo debe resaltarse que el amor de Nuestro Señor siempre prevalece, a fin de que cada uno comprenda que todo acto de virtud perfectamente cristiano no tiene otro origen que el amor, ni otro término que el amor" (Catecismo de la Iglesia Católica, n. 25)» ${ }^{22}$.

Por lo demás, existe un amplio consenso en la actualidad en que la estructura cuatripartita del Catecismo, y la recíproca conexión de sus partes, es un criterio hermenéutico de primer orden para la comprensión de sus contenidos $^{23}$. El tratamiento de cada cuestión singular está vinculada con las demás, y todas se iluminan recíprocamente, como señalaba en 1992 san Juan Pablo II en la Const. apost. Fidei depositum, y de nuevo ha sido subrayado ahora en el nuevo Comentario.

${ }^{22}$ Francisco, Discurso a los participantes en un encuentro organizado por el Consejo Pontificio para la Promoción de la Nueva Evangelización con motivo del XXV aniversario del Catecismo de la Iglesia Católica (11 de octubre de 2017), párrafo 5.

23 Vid. Martinelli, R., «Storia e struttura del Catechismo», en Fisichella, R. (a cura di), Catechismo della Chiesa Cattolica. Testo integrale. Nuovo commento teologico-pastorale, 799-812. 


\section{Bibliografía}

ARANDA, A. (ed.), «Creemos y conocemos»: lectura teológica del Catecismo de la Iglesia Católica, Pamplona: Eunsa, 2012.

Fisichella, R. (a cura di), Catechismo della Chiesa Cattolica. Testo integrale. Nuovo commento teologico-pastorale, Roma: Libreria Editrice Vaticana-San Paolo, 2017.

Francisco, Discurso a los participantes en un encuentro organizado por el Consejo Pontificio para la Promoción de la Nueva Evangelización con motivo del XXV aniversario del Catecismo de la Iglesia Católica (11 de octubre de 2017).

González de Cardedal, O. y Martínez Camino, J. A., El Catecismo postconciliar. Contexto y contenidos, Madrid: San Pablo, 1993.

Juan Pablo II, San, Const. apost. Fidei Depositum (11-IX-1992).

Martinelli, R., «Storia e struttura del Catechismo», en Fisichella, R. (a cura di), Catechismo della Chiesa Cattolica. Testo integrale. Nuovo commento teologico-pastorale, 799-812.

Ratzinger, J., «Introducción al Catecismo de la Iglesia Católica», en RAtzinger, J. y SChÖnborn, Ch., Introducción al Catecismo de la Iglesia Católica, Madrid: Ciudad Nueva, 1993, 11-39.

Ratzinger, J., Die Krise der Katechese und ibre Überwindung, Einsiedeln: Johannes Verlag, 1983.

RatZinger, J., «Transmisión de la fe y fuentes de la fe», Scripta Theologica 15 (1983) 9-29.

Ratzinger, J., «Discurso del Emmo. y Revmo. Cardenal Dr. Joseph Ratzinger», Scripta Theologica 30 (1998) 387-393.

RodríGuez, P., «El sentido de los sacramentos según el Catecismo Romano», Scripta Theologica 9 (1977) 951-984.

RoDríguez, P., El manuscrito original del Catecismo Romano. Descripción del material y los trabajos al servicio de la edición crítica del Catecismo del Concilio de Trento, Pamplona: Eunsa, 1985.

Rodríguez, P., «La edición crítica del Catecismo Romano», Scripta Theologica 22 (1990) 539-594.

Rodríguez, P. y LANZETTI, R., El Catecismo Romano: fuentes e bistoria del texto y de la redacción. Bases críticas para el estudio teológico del catecismo del Concilio de Trento (1566), Pamplona: Eunsa, 1982. 
SCHÖNBORN, Ch., «El Catecismo de la Iglesia Católica: ideas directrices y temas fundamentales», en RATZINGER, J. y SCHÖNBORN, Ch., Introducción al Catecismo de la Iglesia Católica, Madrid: Ciudad Nueva, 1993, 43-66.

SCHÖNBORN, Ch., «Criterios de redacción del Catecismo», en GonZÁlEZ DE Cardedal, O. y Martínez Camino, J. A., El Catecismo postconciliar. Contexto y contenidos, Madrid: San Pablo, 1993, 84-93.

SChÖnborn, Ch., «Il Catechismo della Chiesa Cattolica nelle Chiese particolari», en Fisichella, R. (a cura di), Catechismo della Chiesa Cattolica. Testo integrale. Nuovo commento teologico-pastorale, Roma: Libreria Editrice Vaticana-San Paolo, 2017, 813-824. 
RECENSIONES 
